\title{
El programa hispano-marroquí de enseñanza de Lengua Árabe y Cultura Marroquí (LACM) sometido a revisión. Árabe marroquí y amazige, lenguas nativas (L1)
}

\section{The Arabic Language and Moroccan Culture (LACM) Hispano-Moroccan learning program submitted to revision. Moroccan Arabic and Amazigh, native languages (L1)}

\author{
Francisco MOSCOSO GARCíA \\ Profesor titular del Departamento de Estudios Árabes e Islámicos y Estudios Orientales \\ Universidad Autónoma de Madrid \\ francisco.moscoso@uam.es
}

Recibido: diciembre 2012

Aceptado: marzo 2013

\section{RESUMEN}

Presentamos en este trabajo una reflexión sobre la necesidad de tener en cuenta la lengua nativa o materna del alumno en la escuela. Para ello, proponemos que el programa hispano-marroquí de enseñanza de la Lengua Árabe y Cultura Marroquí (LACM) revise sus objetivos e incluya como lengua de enseñanza el árabe marroquí o el amazige (L1), y no el árabe literal (L2). La enseñanza del español (L2) debe de llevarse a cabo en una situación de bilingüismo aditivo y desde unos principios de democracia y no desde la soberanía monolingüe de la L2, ya sea el español, ya el árabe literal.

Palabras clave: lengua primera (L1), lengua segunda (L2), lengua nativa, lengua materna, educación, bilingüismo, árabe literal, árabe marroquí, amazige.

\begin{abstract}
We present in this work a reflection about the need of taking into account the native or mother language of the student in the school. For this reason, we propose that the Hispano-Moroccan learning Program of Arabic Language and Moroccan Culture (LACM) reviews its objectives and includes the Moroccan Arabic or the Amazigh (L1) as language of learning instead of the Standard Arabic (L2). The learning of Spanish (L2) has to be done in a situation of additive bilingualism and founded on democratic principles and not from the monolingual sovereignty of the L2, either the Spanish or the Standard Arabic.

Keywords: first language (L1), second language (L2), native language, mother language, education, bilingualism, standard Arabic, modern Arabic, Moroccan Arabic, Amazigh.
\end{abstract}

SUMARIO: 0. Introducción, 1. Árabe literal y árabe marroquí, 2. El programa de lengua árabe y cultura marroquí (LACM), 3. Enseñar la L1 para mejor acceder a la L2, 4. Conclusiones. 


\section{INTRODUCCIÓN}

En trabajos anteriores, hemos abordado la situación lingüística de Marruecos, proponiendo la codificación y normalización del árabe marroquí ${ }^{1}$, la lengua nativa del $65 \%$ de la población de Marruecos ${ }^{2}$, demostrando que no es un dialecto del árabe literal $\mathrm{o}$ clásico ${ }^{3}$, como erróneamente se argumenta desde algunos almimbares ${ }^{4}$, sino una lengua con la que es posible -con todas igualmente-crear cualquier tipo de pensamiento, tanto de forma oral como escrita ${ }^{5}$. Y además, teniendo en cuenta que es la lengua nativa del $40 \%$ de la población española de Ceuta, en su variante conocida como árabe ceutí, hemos propuesto que se aplique el derecho constitucional al reconocimiento de cooficialidad de la lengua de una parte del territorio nacional para que sirva a todos los menesteres de la población bilingüe y, especialmente, para atajar el alto índice de fracaso escolar -el más alto del territorio nacional- que sufre la ciudad, mucho más acentuado en los colegios en los que hay mayor escolarización de niños y niñas cuya lengua nativa es el árabe ceutí ${ }^{6}$. Otra cuestión interesante de abordar es la consideración que los españoles bilingües de Ceuta tienen de su lengua nativa. Vicente ${ }^{7}$ ha señalado que es una cuestión de "identidad cultural y religiosa", aunque la mayor parte cree que "habla un mal

${ }^{1}$ Cf. MOSCOSO GARCÍA, Francisco. «Situación lingüística en Marruecos: árabe marroquí, beréber, árabe estándar, lenguas europeas». Al-Andalus-Magreb 10 (2002-2003), 167-186; MOSCOSO GARCÍA, Francisco. «La pentaglosia en Marruecos. Propuestas para la estandarización del árabe marroquí». Miscelánea de Estudios Árabes y Hebraicos 59 (2010a), 45-62; MOSCOSO GARCÍA, Francisco. « L'arabe marocain, une langue minoritaire étrangère parmi d'autres langues minoritaires en Espagne ». En: Colloque international 'La langue, les langues', Casablanca, Fondation Zakoura Education, 11 et 12 juin 2010. Casablanca: Fondation Zakoura Education, 2010b, 287-299.

${ }^{2}$ El último censo nacional hecho en Marruecos data de 2004 y contabiliza un total de $28,2 \%$ de población cuya lengua materna o nativa es el amazige en alguna de sus tres variantes (tārî́fit, tāma āzig̀t o $t \bar{a} s ̌ e \bar{l} l h \bar{\imath} t$ ): http://www.hcp.ma/Recensement-general-de-la-population-et-de-l-habitat-2004_a633.html (última consulta: 19/02/2013). Otras cifras han sido dadas, pero sin un estudio exhaustivo. Algunos, como la web Ethnologue (http://www.ethnologue.com/show_language.asp?code=tzm última consulta: 22/02/2013), hablan de hasta un $40 \%$ de amaziges. Nos ha parecido situar la cifra en un punto intermedio, en torno al $35 \%$.

${ }^{3}$ Cf. MOSCOSO GARCÍA, Francisco. «El árabe marroquí: una lengua y no un dialecto. Educar en la lengua materna». Revista de Estudios Internacionales Mediterráneos 10 (enero-junio 2011), 134-144.

${ }^{4}$ Acerca de esta cuestión, cf. lo dicho en $\S 1$ titulado 'Ibn Jaldún y la defensa de lo imposible' en MOSCOSO GARCÍA, Francisco. «De Ibn Jaldún al reconocimiento del árabe marroquí como una lengua nativa viva y creativa». Miscelánea de Estudios Árabes y Hebraicos 62 (2013), 129-151.

${ }^{5}$ Cf. MOSCOSO GARCÍA, «De Ibn Jaldún al reconocimiento del árabe marroquí... », 145-149.

${ }^{6} \mathrm{Cf}$. MOSCOSO GARCÍA, Francisco. «El árabe de Ceuta: argumentos para su cooficialidad». En: Actas de V Congreso Internacional de Árabe Marroquí. Madrid, Casa Árabe, 27 y 28 de abril de 2012. Cuenca: Ediciones de la Universidad de Castilla-La Mancha, 2013, págs. 95-124. Sobre el árabe ceutí, puede consultarse el estudio sociolingüístico que aparece en VICENTE, Ángeles. Ceuta: une ville entre deux langues. Une étude sociolinguistique de sa communauté musulmane. París: L'Harmattan, 2005. Traducción al español: Vicente, Ángeles. Ceuta: una ciudad entre dos lenguas. Ceuta: Instituto de Estudios Ceutíes, 2008.

${ }^{7}$ Cf. VICENTE, Ceuta: une ville..., págs. 61-69. 
árabe". Rivera ${ }^{8}$ habla de un sentimiento de inseguridad tanto en árabe ceutí como en español por parte de los jóvenes bilingües y de que estos piensan que su lengua nativa, el árabe ceutí, no es una lengua. Aunque -según esta profesora- "se está produciendo una revalorización del árabe ceutí, puesto que este código se ha convertido en una seña de identidad".

Seguiremos, en este artículo, arrojando datos e ideas que corroboran la necesidad de tener en cuenta que el árabe marroquí y el amazige son lenguas nativas que deben de emplearse en la escuela, ya que el desarrollo cognitivo del niño o la niña tiene que asentarse primero en su L1 (lengua primera) para luego incorporar la L2 (lengua segunda) con un mayor índice de éxito. Cuando hablamos de L2, nos vamos a referir al español -que bien podría ser el catalán, gallego, euskera o amazige, lenguas de nuestro territorio nacional- y al árabe literal o clásico. Las competencias en esta última lengua -que no es nativa de ningún árabe, aunque sea una lengua de cultura y administrativa en el Mundo Árabe- podrían ser muchísimo mejores si el alumno comenzara su etapa educativa adquiriendo la lectoescritura en árabe marroquí. Nuestra escuela nos recuerda Mijares ${ }^{9}$ ha dejado de ser monolingüe, pasando a ser plurilingüe, habiendo asentado nuestro sistema educativo en 1990 con la LOGSE sigue diciéndonos esta autora ${ }^{10}$ en otra obra las bases para "la atención a la diversidad" con la finalidad de "atender a todos aquellos colectivos de alumnos a los que, por diversas razones, se les supone que necesitan una ayuda complementaria para alcanzar los requerimientos escolares".

La Guía práctica del profesorado de lengua árabe y cultura marroquí, aparecida en el 2009 parte de la idea de "atender a la diversidad del alumno" con el fin de que sirva como "elemento de reflexión pedagógica" para la enseñanza de la lengua árabe y la cultura marroquí (LACM) ${ }^{11}$. Esta guía está dirigida desde el Ministerio de Educación y coordinada por este y por la embajada de Marruecos; el grupo de trabajo que la ha elaborado está compuesto por profesores españoles y miembros de la Misión Cultural Marroquí en Madrid. En nuestro trabajo,

${ }^{8}$ Cf. RIVERA REYES, Verónica. "Características del bilingüismo español-árabe dariya en Ceuta». En: Escenarios bilingües. El contacto de lenguas en el individuo y la sociedad. Christian Abelló Contesse, Christoph Ehlers \& Lucía Quintana Hernández (eds.). Berna - Berlín - Bruselas Frankfurt am Main - Nueva York - Oxford - Viena: Peter Lang, 2010, pp. 211-236, pág. 231-233.

${ }^{9}$ Cf. MIJARES MOLINA, Laura. «El programa ELCO marroquí». En: Multiculturalidad y educación. Teorías, ámbitos y prácticas. Tomás Fernández García \& José G. Molina (coords.). Madrid: Alianza Editorial, 2005, 334-352, pág. 335.

${ }^{10}$ Cf. MIJARES MOLINA, Laura. Aprendiendo a ser marroquies. Inmigración, diversidad lingüistica y escuela. Madrid: Ediciones del Oriente y del Mediterráneo, 2006, 214.

${ }^{11}$ Cf. Enseñanza de la Lengua y Cultura de Origen. Lengua Árabe y Cultura Marroquí. Guía práctica del profesorado de lengua árabe y cultura marroquí. Ministerio de Educación \& Embajada de Marruecos en Madrid (eds.), 2009, 15. En:

http://www.mecd.gob.es/dctm/ministerio/educacion/sistema-educativo/educacionintercultural/programa-hispanomarroqui/guiapracticacastellano.pdf?documentId=0901e $72 \mathrm{~b} 80 \mathrm{edec} 45$ (última consulta: 11/12/2012). 
analizaremos algunos de los presupuestos de esta guía y demostraremos que se olvida la lengua nativa del alumno, el árabe marroquí o el amazige en cualquiera de sus tres variantes, y que el árabe literal no es lengua nativa de ningún árabe. Desde esta tesitura, daremos argumentos para que la L1, árabe marroquí o amazige, sea tenida en cuenta en el sistema educativo, para luego acceder de manera más cómoda e inteligente a la L2, español o árabe literal.

Por otro lado, es importante acercarse a la diversidad y atenderla desde unas bases sólidas que nos permitan ir construyendo la pluralidad de forma positiva. Abu-Shams ${ }^{12}$ dice que la educación intercultural debe ser un reto para la escuela, ya que "del reconocimiento de la existencia de la diversidad cultural entre el alumnado depende en buena medida una formación satisfactoria y plural que responda a la complejidad de la sociedad actual". Además, al tener en cuenta la lengua nativa, tendremos que abandonar esa idea rancia que sigue pululando por muchos salones educativos que pretenden asirse a un pasado europeo en el que la cultura árabe ha estado ausente para reivindicar una identidad que no puede desembocar más que en intolerancia a todos los niveles, especialmente el educativo. Y que por ignorancia va a parar, sin más explicación, a documentos como el que hemos presentado en el anterior párrafo, en expresiones como la siguiente: "el árabe culto es una lengua con raíces diferentes a las lenguas europeas" ${ }^{13}$. Esto no es totalmente cierto, ya que no debemos olvidar que el maltés es lengua árabe y es lengua oficial de la Unión Europea. Y por otro lado, el documento podría haber recordado que el árabe andalusí fue una lengua de la Península Ibérica desde el siglo VIII hasta el XVII y que el español tiene cerca de dos mil palabras ${ }^{14}$ procedentes de esta lengua en su mayor parte y menos del árabe literal; y también que el árabe ceutí es una lengua minoritaria y sin reconocimiento del Estado Español. Por consiguiente, la lengua árabe y el islam también forman parte de nuestro pasado y el presente europeos.

\section{1. ÁRABE LITERAL Y ÁRABE MARROQUí}

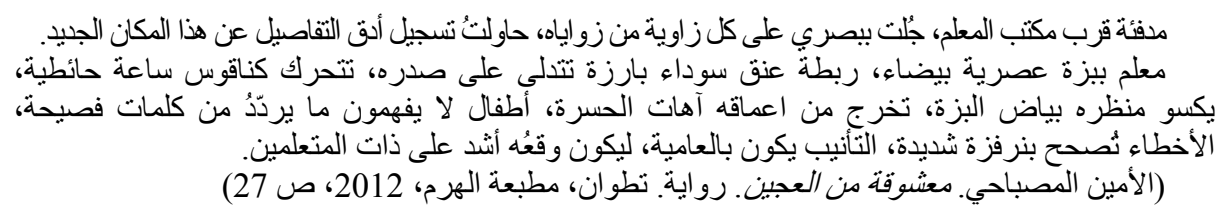

${ }^{12}$ Cf. ABU-SHAMS, Leila. «Educación, lengua y cultura: la escolarización de los niños marroquíes en España». En: Actas del primer congreso Árabe marroquí: Estudio, Enseñanza y Aprendizaje. Cádiz, 27 y 28 de abril de 2006. Nadi Hamdi Nouaouri \& Francisco Moscoso García (eds.). Cádiz: Universidad de Cádiz, 2006, 1-27, pág. 17.

${ }_{13}^{13}$ Cf. Enseñanza de la Lengua y Cultura de Origen, 27.

${ }^{14} \mathrm{Cf}$. Sobre esta cantidad, cf. el prólogo escrito por Federico Corriente en la obra VICENTE, Ángeles. El proceso de arabización de Alandalús. En: Guías de Historia, Arte y Cultura Islámica 4. Zaragoza, Instituto de Estudios Islámicos y del Oriente Próximo, 2006. 
"Había una estufa cerca de la mesa del maestro, pasé mi mirada por todos los rincones, intenté grabar hasta el más mínimo detalle de aquel lugar nuevo.

Un maestro con un traje moderno blanco, corbata negra prominente que caía sobre su pecho, y que se movía como el péndulo de un reloj de pared, su aspecto era como el de la blancura del traje y de su interior salían suspiros de aflicción. Los niños no entendían las palabras clásicas que repetía, los errores eran corregidos con gran nerviosismo. La reprimenda era en dialecto, para que su impacto calara más hondo en los alumnos".

(El Misbahi, El Amin. Una amada hecha de masa. Novela. Tetuán, Maṭbåa alHaram, 2012, 27).

Los hechos que describe el novelista chauní tuvieron lugar a mediados de los años sesenta, más o menos, en la escuela. Podemos imaginarnos la situación: un maestro que enseña en árabe literal y unos alumnos cuya lengua nativa era el árabe marroquí, además de una metodología primitiva, basada en la repetición y la memorización. El informe Le Maroc posible ${ }^{15}$, publicado unos treinta y nueve años después de la situación que vive El Misbahi, arroja una cifra media de un cuarenta y cinco por ciento de analfabetismo en Marruecos, constatando que hay un desequilibrio entre la lengua nativa -árabe marroquí o amazige- y el árabe literal, la lengua de enseñanza, cuyas competencias en el sistema educativo dejan que desear, provocando 'inseguridad lingüística'. En una entrevista hecha a Abdallah Laroui en la revista de Historia Zamane ${ }^{16}$, este historiador fue preguntado por su visión de la arabización. $\mathrm{Su}$ respuesta fue la siguiente: [...] Quant à l'arabisation, je la défendais parce que je pensais que c'était le chemin le plus court pour alphabétiser les populations ; c'est pour cela que je demandais aussi une simplification, à tous les niveaux, de cette langue véhiculaire. Et cependant, même sur ce plan là, je prévoyais qu'à une certaine étape l'alphabétisation aboutirait par elle-même à une diversification et que l'idiome arabe marocain serait différent des autres ${ }^{17}$. Sin embargo, esta etapa no ha llegado todavía, ya que los intereses políticos y religiosos tienen secuestrada la lengua y la educación. No profundizaremos en esta cuestión sino que remitimos al lector al segundo apartado de un trabajo en el que abordamos detalladamente esta situación ${ }^{18}$.

Lázaro Carreter ${ }^{19}$ nos recuerda que las primeras valoraciones sobre el origen del lenguaje se remontan al siglo $\mathrm{V}$ a. $\mathrm{C}$. Entonces se esbozaban las dos teorías que han

${ }^{15} \mathrm{Cf}$. Le Maroc possible. Une offre de débat pour une ambition collective. 50 ans de développement humain. Perspective 2025. Casablanca: Éditions Maghrébines, 2006, 110-113.

${ }^{16}$ Cf. BENCHEIKH, Souleïman, BOUAZIZ, Mostafa \& MONJIB, Maâti. 2012. « Abdallah Laroui, 'Le Magreb est l'idée d'une élite' ». L'Histoire du Maroc. Zamane 18 (avril 2012), 62-69, pág. 66.

${ }^{17}$ Traducción: “[...] en cuanto a la arabización, la defendía porque pensaba que era el camino más corto para alfabetizar a las poblaciones; por ello, pedía también una simplificación, a todos los niveles, de esta lengua vehicular. Y sin embargo, incluso en esta tesitura, preveía que a una determinada etapa, la alfabetización desembocaría por sí misma en una diversificación y que el idioma árabe marroquí sería diferente de los otros".

${ }^{18} \mathrm{Cf}$. MOSCOSO, «El árabe marroquí....».

${ }^{19}$ Cf. LÁZARO CARRETER, Fernando. "Las ideas lingüísticas en España durante el siglo XVIII." En: Revista de Filología Española XLVIII. Madrid: CSIC, Patronato Menéndez Pelayo, Instituto Miguel de Cervantes, 1949, 20-21. 
sobrevivido casi hasta nuestros días. Por un lado estaba Heráclito, quien defendía el origen divino del lenguaje, y por el otro Demócrito, quien sostenía que tenía un origen convencional, ya que el hombre estaba necesitado de comunicarse. Esta dualidad perdurará gracias a Platón y Aristóteles respectivamente. De ella no está libre el discurso religioso islámico -vigente hoy día-, y así, los que no reconocen la hermenéutica llegan a afirmar que el árabe clásico en el que fue escrito el texto sagrado tiene un origen divino y que el resto de lenguas árabes son una deformación o vulgarización que tienen su origen en él. Este argumento, desde la racionalidad y la lingüística moderna, no tiene ningún peso. Ya argumentamos ${ }^{20}$ que el árabe en el que fue escrito el Corán era una más de las hablas árabes existentes en el momento de la revelación, la cual era empleada como lengua de prestigio. Poco se sabe de un protoárabe que sí pudo ser la lingua mater de todos los registros árabes que han llegado hasta nuestros días. Lo único que nos queda es la hermandad de todas ellas -incluido el árabe literal- reconocible a través del sistema de raíces.

El arabismo español se ha volcado tradicionalmente en el estudio del árabe literal a partir del texto -especialmente en el tema de al-Andalus en todas sus facetas-, dejando en un segundo plano la oralidad contemporánea, incluso a veces desechándola. Ni qué decir tiene que el estudio del árabe marroquí fue expulsado, hasta fechas recientes, de los planes de estudio, considerándose su aprendizaje una labor de segunda categoría a la que se dedicaron los llamados 'africanistas', que no solo aparecieron en el Protectorado, sino también en el siglo XIX, y ello a pesar de los intentos de Julián Ribera por que se estudiara el árabe marroquí ${ }^{21}$. Vermeren ${ }^{22}$ afirma que la Francia del siglo XIX abordó el estudio de las humanidades centrándose en la gramática, la filología y estudio de la lenguas vivas europeas del momento, señalando que ce trait général devint constitutif dans l'apprensitssage de l'arabe en France, avec lequel, à certains égards, l'INALCO (ex-Langues orientales) $n$ 'a jamais rompu ${ }^{23}$. El estudio se centró en el árabe literal y se dejaron en un segundo plano los dialectos árabes, todavía llamados -dice este autor'lenguas vulgares' en el libro del bicentenario publicado por el INALCO en 1995. Hay un dato curioso que nos refiere Mijare ${ }^{24}$ y que viene a ahondar en lo dicho por Vermeren en relación al sistema educativo francés. Los arabistas franceses pidieron hace unos años que no se pusiera en práctica la iniciativa que pretendía examinar de

${ }^{20}$ Cf. MOSCOSO, «La pentaglosia en Marruecos...», 48-51.

${ }^{21}$ Cf. MOSCOSO GARCÍA, Francisco. «Árabe marroquí: vulgar y dialectal. El interés por su aprendizaje y su metodología de estudio durante el Protectorado español». En: Revista de Estudios Internacionales Mediterráneos 12 (enero-junio 2012), 183-220, págs. 185-189.

${ }^{22}$ Cf. VERMEREN, Pièrre. Misère de l'historiographie du 'Maghreb' post-colonial 1962-2012. Paris: Publications de la Sorbone, 2012, 25.

${ }^{23}$ Traducción: «este rasgo general se convirtió en constitutivo en el aprendizaje del árabe en Francia, con el que, en ciertos aspectos el INALCO (ex-Lenguas Orientales) no ha roto nunca».

${ }^{24}$ MIJARES, Aprendiendo a ser marroquies, 344. 
árabe marroquí en selectividad, y que solo se hiciera del árabe literal. La consecuencia fue la disminución considerable de los alumnos de árabe literal ${ }^{25}$.

\section{EL PROGRAMA DE LENGUA ÁRABE Y CULTURA MARROQUÍ (LACM)}

Este programa se enmarca dentro del Convenio Hispano-Marroquí de Cooperación Cultural, firmado en 1980 y en vigor cinco años más tarde, aunque no se implanta hasta el curso 1994-1995. El objetivo de este programa, antes llamado ELCO (Enseñanza de la Lengua y Cultura de Origen) -señala Mijares ${ }^{26}$-, es "el de implementar políticas lingüísticas acordes con las que son las características de las escuelas actuales, espacios multiculturales y plurilingües en los que se busca fundamentalmente, al menos desde el punto de vista teórico, llevar a cabo prácticas pedagógicas interculturales". Y está dirigido "al alumno marroquí escolarizado en centros educativos españoles de Educación primaria y secundaria" ${ }^{27}$. Los datos de este documento nos permiten saber que en el curso 2008-2009 -no hay información actualizada publicada por el Ministerio- está implantado en trece comunidades autónomas. El objetivo principal es la enseñanza de la Lengua Árabe y la Cultura Marroquí en dos modalidades: A, para centros con pocos alumnos y en horario extraescolar, y $\mathrm{B}$, para centros con un elevado número de alumnos y con clases en horario lectivo. En el primero de los casos, un profesor marroquí atiende varios centros y en el segundo, se asigna a un profesor por centro. Un dato importante a tener en cuenta es que la selección y nombramiento del profesorado es hecha por Marruecos entre los profesores funcionarios. Este dato es significativo, ya que nos encontramos con un sistema de enseñanza calcado del marroquí, que, por un lado, no tiene en cuenta la lengua nativa del alumno, y por otro, no sabemos hasta qué punto tiene en cuenta las especificidades del niño de origen marroquí que está creciendo en nuestro país y se educa en el sistema español, aunque sí es cierto que se garantiza la formación del profesorado marroquí. Recordemos que en el epígrafe anterior hablábamos del alto índice de analfabetismo de Marruecos que el informe Le Maroc

${ }^{25}$ Sobre esta cuestión, cf. CAUBET, Dominique. «L'épreuve d'arabe dialectal au Bac. Passage à l'écrit - Bilan comparatif de sessions 1996 y 1995». En: Enseignement de la langue d'origine et immigration nord-africaine en Europe. Langue maternelle ou langue d'État? M. Tilmatine (ed.). París, INALCO, 1997, 163-172; CAUBET, Dominique. «Arabe maghrébin: passage à l'écrit et institutions». En : Faits de Langues. Oral-Écrit: Formes et théories 13 (1999), 235-244; y VICENTE, Ángeles. «El árabe dialectal suspendido en el bachillerato francés». En: Estudios de Dialectología Norteafricana y Andalusi 4 (1999), 135, 148.

${ }^{26}$ MIJARES, Aprendiendo a ser marroquies, 48.

${ }^{27}$ Cf. Programa hispano-marroqui de enseñanza de Lengua Árabe y Cultura Marroquí (LACM). Educación \& Embajada de Marruecos en Madrid (eds.), 2009, 1. En:

http://www.mecd.gob.es/dctm/ministerio/educacion/sistemaeducativo/educacion-intercultural/ programa-hispano-marroqui/lacm.pdf?documentId=0901e72b80edec46 (última consulta: 11/12/2012). 
posible achaca, entre otros factores, al desequilibrio entre la lengua nativa o materna y la lengua de enseñanza, el árabe literal, que no es lengua nativa de ningún árabe.

En cuanto al material educativo que se emplea está formado por un libro con indicaciones pedagógicas para la enseñanza del árabe y la cultura marroquí, elaborado por el Ministerio de Educación Nacional de Marruecos, una Guía Práctica $^{28}$, un libro destinado a la enseñanza del español y una serie de unidades didácticas en proyecto de elaboración. Estos tres últimos materiales han sido dirigidos desde el Ministerio de Educación de España ${ }^{29}$.

La Guía práctica prevé "renovar la metodología para asegurar el progreso en el aprendizaje significativo que solucione los problemas percibidos actualmente por los profesores que trabajan en el programa" ${ }^{30}$. Si bien este principio es loable, los presupuestos siguientes chocan de lleno con la pedagogía. Se dice que el niño "se expresa y habla en castellano y se suele comunicar con sus parientes en un 'dialecto magrebí", argumentando que "el árabe es para estos alumnos y alumnas una lengua que pertenece a su patrimonio cultural, pero que desconocen por falta de uso" ${ }^{31}$. Efectivamente, el árabe -aquí se entiende el literal-es patrimonio cultural, pero no es lengua nativa de los marroquíes. En las observaciones destacadas anteriormente, se desvelan cuáles son los principios educativos institucionales de Marruecos, que evitando la expresión "lengua nativa o materna" se camufla en la de "dialecto magrebí", como si la única lengua por excelencia fuera la clásica, y esto teniendo en cuenta, como ya hemos argumentado, que el árabe marroquí no deriva del árabe literal o clásico. Por otro lado, cabe destacar que la lengua nativa del $35 \%$ de la población marroquí es el amazige - marginada en los acuerdos- y que esta se enseña en la escuela marroquí desde principios de los años diez del presente siglo. Hasta no hace poco, julio de 2011, no se ha introducido el amazige como lengua oficial en la Constitución marroquí, siendo hoy por hoy oficiales el árabe se entiende el literal, no el árabe marroquí y el amazige. No es necesario entrar en más comentarios sobre los principios pedagógicos de esta guía, ya que están dirigidos al árabe literal. Solo concluiremos que echamos en falta unos indicadores más concretos que puedan medir el nivel de competencias adquiridas por los alumnos con el fin de poder observar la viabilidad de la enseñanza de una lengua que no es la L1 de estos niños y niñas.

Por consiguiente, después de lo expuesto en el párrafo anterior, si se tuviera en cuenta lo dicho en la Guía práctica, a saber, la "necesidad de partir del nivel de desarrollo de los alumnos y de las alumnas, de sus conocimientos previos, experiencias e intereses, respetando sus estadios evolutivos y sus posibilidades de aprendizaje" ${ }^{32}$, se partiría de la enseñanza de la lengua nativa, el árabe marroquí o el amazige, ya que este

${ }^{28}$ Cf. Enseñanza de la Lengua.

${ }^{29} \mathrm{Cf}$. Programa hispano-marroqui, 6.

${ }^{30} \mathrm{Cf}$. Enseñanza de la Lengua, 25.

${ }^{31} \mathrm{Cf}$. Enseñanza de la Lengua, 26.

${ }^{32} \mathrm{Cf}$. Enseñanza de la Lengua, 49. 
es el estadio primero y necesario del desarrollo cognitivo del niño que entra en la escuela. Y aún más, si "el profesor, por tanto, no es solo alguien que transmite una nueva lengua, sino más bien alguien que ayuda a los alumnos a desarrollar una capacidad natural para comunicarse con las gentes de su país de origen", la pregunta está clara: ¿por qué enseñar el árabe literal y no el árabe marroquí o el amazige? Mijares $^{33}$ ya advertía de que, por un lado, la enseñanza del árabe es extracurricular, no cuenta en el expediente del alumno, lo cual hace que este no la tome en serio como debiera, y, por otro, para la autora, la razón de mayor peso es que "los responsables del programa, tanto en España como en Marruecos, siguen aludiendo a los viejos preceptos -aquellos que abogan por la preparación para el retorno o la salvaguarda de unas supuestas raíces culturales fijas y específicamente marroquíes- para justificar su existencia". Y, como factor que corrobora nuestro planteamiento, Mijares ${ }^{34}$ apunta más adelante que el programa marroquí "solo contempla el aprendizaje de la lengua árabe estándar", es decir, el árabe literal o clásico.

Ya en 1999, el arabista holandés De Ruiter ${ }^{35}$, cuatro años después de la puesta en práctica de la ELCO en España, se pregunta si se debe enseñar el árabe literal o el árabe marroquí "sobre todo si se toma en consideración que ella (el árabe literal) no juega un papel tan importante en Europa como en Marruecos". Entonces, este investigador ponía de manifiesto que en Holanda y Alemania se habían llevado a cabo estudios cuyas conclusiones decían que el nivel del árabe literal entre los alumnos que seguían cursos era bajo y que, además, las competencias de la lengua nativa eran inferiores a las de la lengua de la sociedad de acogida ${ }^{36}$. Este autor propone la enseñanza de la L1 (árabe marroquí o amazige) tomando "consciencia" del tronco común y no común con el árabe literal, la L2. Sin embargo, no estamos de acuerdo con su idea de que la L1 "permanecerá sobre todo oral" y la L2 será "antes que nada escrita", ya que la L1, a pesar de no estar normalizada, posee hoy en día textos abundantes procedentes de la tradición popular (cuentos, historias, poesía popular...), novelas y traducciones de obras literarias europeas que prueban que la lengua nativa es, como todas, creativa y con ella se puede desarrollar la lectoescritura ${ }^{37}$. Siguiendo en esta línea, el profesor Arias $^{38}$ ponía de relieve que los

${ }^{33}$ Cf. MIJARES, Aprendiendo a ser marroquies, 251.

${ }^{34}$ Cf. MIJARES, Aprendiendo a ser marroquies, 329.

${ }^{35}$ Cf. DE RUITER, Jan Jaap. «Árabe estándar y árabe dialectal en la enseñanza de la lengua y cultura de origen (ELCO) marroquí en Europa». En: Lengua y cultura de origen: niños marroquíes en la escuela española. En: Taller de Estudios Internacionales Mediterráneos. Adela Franzé (ed.) \& Laura Mijares Molina (col.) Madrid: Ediciones del Oriente y del Mediterráneo, 1999, 123-142, pág. 124.

${ }^{36}$ Cf. DE RUITER, «Árabe estándar y árabe dialectal...», 127.

${ }^{37}$ Cf. MOSCOSO, «De Ibn Jaldún al reconocimiento del árabe marroquí...», 147-150.

${ }^{38}$ Cf. ARIAS, Juan Pablo. «Profesores al borde de un ataque de nervios: didáctica del árabe para escolares inmigrantes». En: Lengua y cultura de origen: niños marroquies en la escuela española. En: Taller de Estudios Internacionales Mediterráneos. Adela Franzé (ed.) \& Laura Mijares Molina (col.) Madrid: Ediciones del Oriente y del Mediterráneo, 1999, 201-211, págs. 203-205. 
profesores marroquíes que enseñan el árabe literal dependen bastante de sus "esfuerzos individuales", además de que no todos dominan el árabe literal ni tienen una adecuada formación didáctica para la enseñanza de esta lengua. Arias ${ }^{39}$ es rotundo al afirmar que, aunque la enseñanza del árabe literal sea importante, no contribuye a hacer frente a "los problemas iniciales de integración y acogida de los escolares inmigrantes de origen magrebí, ya que estos, en el caso de que su lengua primera no sea el español, nunca tendrán el árabe clásico como lengua materna".

El absurdo de no enseñar la lengua nativa tiene su expresión en declaraciones como las de un inspector de enseñanza marroquí que participó en la obra colectiva Lengua y Cultura de Origen ${ }^{40}$, afirmando que los objetivos lingüísticos del programa persiguen la adquisición de "la expresión oral, aprender a leer y escribir, lo cual permitirá al alumno entrar en relación fácilmente con sus conciudadanos, tanto en Marruecos como fuera del país". En el caso de que un alumno adquiera las competencias necesarias para hablar en árabe literal, este se sentirá desplazado, ya que las lenguas nativas que se hablan en la calle, e incluso en la administración, son el árabe marroquí y el amazige. En la misma línea, aunque vislumbrando la dificultad de la enseñanza de una lengua no nativa y con carácter sintético, se manifiesta un profesor del programa ${ }^{41}$, al decir que "los resultados son en general positivos", pero se queja del poco tiempo dedicado a la enseñanza, de que "el programa no responde a la realidad lingüística del aprendiz" y de "la dificultad de las estructuras gramaticales y la diversidad de temas". El profesor Fouad Laroui ${ }^{42}$ ha calificado últimamente la imposición del árabe literal en la escuela desde el principio de la etapa educativa como responsable de la "esquizofrenia nacional". Si hablamos de un $45 \%$ de analfabetismo, las competencias en árabe literal de la población alfabetizada no son aceptables. Los alumnos según me han contado algunos profesores de facultades de letras en Marruecos llegan a la universidad con un nivel bajo en árabe literal.

La puesta en práctica de "la atención a la diversidad" establecida por la LOGSE (1990) en muchas comunidades autónomas ha sido la creación de las "aulas de enlace", llamadas así o con otros nombres, "aulas de adaptación lingüística", "aulas puente", "aulas de inmersión lingüísticas" ${ }^{43}$. Contamos con los resultados de un

${ }^{39} \mathrm{Cf}$. ARIAS, «Profesores al borde de un ataque de nervios...», 205.

${ }^{40} \mathrm{Cf}$. NECHDA, Mohamed. «La enseñanza de la lengua árabe y la cultura marroquí (LACM) en España». En: Lengua y cultura de origen: niños marroquies en la escuela española. En: Taller de Estudios Internacionales Mediterráneos. Adela Franzé (ed.) \& Laura Mijares Molina (col.) Madrid: Ediciones del Oriente y del Mediterráneo, 1999, 179-181, pág. 180.

${ }^{41} \mathrm{Cf}$. RADI, Mostafa. «La enseñanza de la lengua árabe y cultura marroquí en la práctica». En: Lengua y cultura de origen: niños marroquies en la escuela española. En: Taller de Estudios Internacionales Mediterráneos. Adela Franzé (ed.) \& Laura Mijares Molina (col.) Madrid: Ediciones del Oriente y del Mediterráneo, 1999, 183-189.págs. 183-185.

${ }^{42}$ Cf. LAROUI, Fouad. Le drame linguistique marocain. Léchelle: Zellige, 2006, 98.

${ }^{43}$ Cf. VILLADA PRIETO, Marta. "ATAL y ELCO: dos programas para el desarrollo de la competencia lingüística». Temas para la Educación 6 (enero de 2010), 1-6. En: 
estudio interesante llevado a cabo por Pérez ${ }^{44}$ en el que se pone de manifiesto la dificultad de este tipo de aulas para el profesor. Se trataba de un aula en la que estaban representadas multitud de lenguas y en la que había que garantizar la enseñanza del español. Se partía de un principio equivocado derivado de "una visión según la cual para aprender una lengua hay que olvidar la otra, no pensar en ella" ${ }^{45}$. Lo interesante del análisis de este investigador es que los profesores que con posterioridad acogían a estos niños en sus aulas, dentro del ciclo de estudios, se quejaban de que tenían un nivel bajo de español y no podían seguir el ritmo de las clases $^{46}$. Este autor concluye que un programa cuyo objetivo es la "atención a la diversidad" puede terminar marginando a los alumnos y alumnas ${ }^{47}$. Apoyando lo dicho por este autor, Cummins ${ }^{48}$ destaca que "la mayoría de los defensores académicos de la educación bilingüe se han manifestado de forma contundente en contra de los programas de transición rápida, por considerarlos muy inferiores a los programas que tratan de desarrollar el bilingüismo y la lectoescritura bilingüe".

En el siguiente apartado, haremos propuestas para la enseñanza del árabe marroquí, o el amazige, en nuestras escuelas de primaria y secundaria que sirvan para mejorar la Guía práctica para la enseñanza de la Lengua Árabe y Cultura Marroquí (LACM).

\section{ENSEÑAR LA L1 PARA MEJOR ACCEDER A LA L2}

Mijares ${ }^{49}$ señala que en los últimos años entidades como la Unión Europea o el Consejo de Europa han desarrollado una serie de líneas de actuación conducentes a que los países miembros lleven a cabo "políticas de integración teniendo en cuenta cuestiones fundamentales como la diversidad cultural y/o lingüística". Y este es el caso del programa que nos ocupa en este trabajo. Nosotros, en contra de las políticas asimilacionistas que van en detrimento de la lengua nativa, como es el caso de Francia, proponemos la enseñanza de la lengua nativa (L1) y no el árabe

http://www2.fe.ccoo.es/andalucia/indconte.aspx?d=3977\&s=5\&ind=180 (última consulta: 11/12/2012); y GARCÍA CASTAÑO, Francisco Javier, RUBIO GÓMEZ, María \& BOUACHRA, Ouafa. «Población inmigrante y escuela en España: un balance de investigación». Revista de Educación 345 (enero-abril de 2008), 23-60.

${ }^{44}$ Cf. PÉREZ MILANS, Miguel. «Las aulas de enlace: un islote de bienvenida». En: Voces del aula. Etnografias de la escuela multilingüe. En: Colección de ESTUDIOS CREADE 3. Luisa Martín Rojo y Laura Mijares (eds.). Madrid: Ministerio de Educación y Ciencia, CIDE, 2007, 111-146.

${ }^{45}$ Cf. PÉREZ, «Las aulas de enlace...», 131.

${ }^{46} \mathrm{Cf}$. PÉREZ, «Las aulas de enlace...», 140.

${ }^{47}$ Cf. PÉREZ, «Las aulas de enlace...», 146.

${ }^{48}$ Cf. CUMMINS, Jim. Lenguaje, poder y pedagogía. Madrid: Ministerio de Educación, Cultura y Deporte - Ediciones Morata, 2002, 193.

${ }^{49}$ Cf. MIJARES MOLINA, Laura. «Políticas europeas de integración del alumnado inmigrante: una mirada comparativa». Colección materiales de Aula Intercultural (enero de 2009), nº 1, 1-24, págs. 5-6. 
literal, que debiera ser una L2, al igual que el español. Esta filosofía fue la de los Países Bajos hasta hace pocos años, habiendo evolucionado hacia el asimilacionismo $^{50}$. Cualquier lengua del mundo es un instrumento de expresión y creación tan válido como el español o el inglés. En un mundo en el que se hace valer por encima de todo la producción en inglés, como imposición del imperialismo, deberíamos de volver la mirada hacia nuestras propias lenguas, las que han estado desde hace tiempo y las que han llegado junto a los inmigrantes. El árabe marroquí puede ser tan capaz de servir a un novelista como a un físico. Es cierto que para adaptarse a ciertas disciplinas, tiene que ser nutrido de voces y expresiones nuevas. Todas las lenguas se han alimentado de palabras procedentes de otras. Como apunta acertadamente Ruiz ${ }^{51}$ “[...] el inglés en el siglo XIII no era un idioma con el que podríamos haber hablado entonces de teléfonos móviles, de aparatos de radiografía ni de autopistas de la información". Y además, este mismo autor, argumenta que la educación plurilingüe otorgará al alumno mayores destrezas lingüísticas que repercutirán positivamente en su futuro profesional, contribuyendo así al desarrollo económico de un país ${ }^{52}$.

Vygotsky ${ }^{53}$ puso de manifiesto que existe una relación muy estrecha entre pensamiento y la lengua nativa, de forma que si impedimos el desarrollo de esta, estamos coartando el desarrollo cognitivo del niño. Y en relación al bilingüismo, Cummins $^{54}$ ha destacado que cuando se estimulan los dos idiomas convenientemente, se adquiere un mejor desarrollo lingüístico, cognitivo y académico. Partiremos en nuestra reflexión de estas dos premisas para proponer la enseñanza del árabe marroquí o el amazige: la necesidad de desarrollar la lengua nativa y lo positivo de un bilingüismo bien entendido a través de una lectoescritura adecuada a cada una de las lenguas y a cada contexto sociolingüístico. Desde ellas se debe iniciar el proceso educativo del alumno. Este bilingüismo debe de ser aditivo, es decir, permitir que el desarrollo de la L2 se produzca sin que vaya en detrimento de la L1, estimulándola y permitiendo que siga su proceso de crecimiento conceptual y académico.

Lo contrario a lo expuesto anteriormente puede derivar en un "analfabetismo de opresión" 55 . En España tenemos un claro ejemplo en Ceuta, en donde el fracaso escolar es el más elevado del territorio nacional, mucho más acentuado en aquellos colegios en donde hay un mayor número de alumnos bilingües ${ }^{56}$. Poco o nada se

${ }^{50}$ Cf. MIJARES, «Políticas europeas de integración...», 10-15.

${ }^{51}$ Cf. RUIZ VIEYTEZ, Eduardo J. Juntos pero no revueltos. Sobre diversidad cultural, democracia y derechos humanos. Madrid: Maia ediciones, 2011, 146.

${ }^{52}$ Cf. RUIZ, Juntos pero no revueltos, 157.

${ }^{53}$ Cf. VYGOTSKY, Lev. Pensamiento y lenguaje. En: Surcos 3. Barcelona - Buenos Aires México: Paidós, 2010, 226.

${ }^{54} \mathrm{Cf}$. CUMMINS, Lenguaje, 17.

${ }^{55} \mathrm{Cf}$. CUMMINS, Lenguaje, 58.

${ }^{56}$ Cf. JIMÉNEZ GÁMEZ, Rafael. "El uso del dialecto árabe marroquí en Ceuta, defensa frente al poder. Un estudio de caso en un centro de educación secundaria". En: Actas del primer congreso 
hace por salvaguardar la lengua nativa del $40 \%$ de la población española bilingüe de la ciudad autónoma de Ceuta, ya que la diversidad lingüística no es una cuestión relevante en el sistema educativo español ${ }^{57}$. El fracaso escolar está directamente en relación con la opresión -como apuntaba Cummins-, ya que desde el sistema educativo y los organismos que rigen, tanto del Estado Español como de la Ciudad Autónoma de Ceuta, no se entiende que haya que desarrollar una lengua nativa que minusvaloran por ignorancia y de la que tienen miedo por ser también la lengua del $65 \%$ de la población marroquí. Esta actitud no desvela sino la intolerancia que está instalada en los órganos de poder, los cuales no son más que la máscara que cubre la ignorancia y un etnocentrismo español que ha sido construido en oposición a todo lo que sonara a árabe ${ }^{58}$. De esta forma, estamos negando la participación en una sociedad democrática a grupos de ciudadanos, ya sean españoles de Ceuta, ya inmigrantes llegados a nuestra sociedad, o sus hijos nacidos en España, que deben de contribuir al progreso de la misma desde una óptica transformadora e intercultural ${ }^{59}$. Nos ha llamado la atención que en la Facultad de Educación y Humanidades de Ceuta ${ }^{60}$, en los grados de Educación infantil y primaria respectivamente, no haya ninguna asignatura específica que aborde la situación de bilingüismo que se vive en la escuela. En Educación infantil encontramos las asignaturas "atención a la diversidad" y "dificultades del aprendizaje" y en Educación primaria "dificultades del aprendizaje", pero en sus descripciones y objetivos no se atiende a la especificidad ceutí. Es como si se hubieran exportado unas guías de la península y, además, elaboradas antes de la llegada masiva de inmigrantes a nuestro país. La universidad se convierte así en cómplice de la política que se ceba con los ciudadanos bilingües ceutíes, los nacionales de origen marroquí que mantienen su lengua nativa y los ciudadanos marroquíes en general que viven en España.

Es importante, para que se desarrolle el bilingüismo, que el docente y el discente estén en constante negociación ${ }^{61}$. Un factor a tener en cuenta es el de la valoración de la cultura y la lengua nativa del estudiante. Es necesario que el profesor español conozca o intente conocer la cultura marroquí y su diversidad lingüística, aunque no llegue a hablar el árabe marroquí o el amazige. De la misma forma, es importante que el profesor marroquí que participa en el programa de

Árabe marroquí: Estudio, Enseñanza y Aprendizaje. Cádiz, 27 y 28 de abril de 2006. Nadi Hamdi Nouaouri \& Francisco Moscoso García (eds.). Cádiz: Universidad de Cádiz, 2006, 129-149, pág. 133.

${ }^{57}$ Cf. RIVERA REYES, Verónica. «La lengua materna como elemento afectivo y base para el aprendizaje». En: Aula intercultural 2010, pág. 3. En:

http://www.aulaintercultural.org/IMG/pdf/lenguamaterna-vrivera.pdf (última consulta 11/12/2012).

${ }^{58} \mathrm{Cf}$. STALLERT, Christiane. Etnogénesis y etnicidad en España. Una aproximación históricoantropológica al casticismo. Barcelona: Proyecto A ediciones, 1998.

${ }^{59} \mathrm{Cf}$. CUMMINS, Lenguaje, 62-63.

${ }^{60} \mathrm{Cf}$. http://feh-ceuta.ugr.es/pages/banners/estudia_en_ceuta (última consulta: 11/12/2012).

${ }^{61} \mathrm{Cf}$. CUMMINS, Lenguaje, 67. 
LACM ayude a desarrollar la lectoescritura en la lengua nativa del alumno de origen marroquí, dejando el árabe literal para más adelante y siempre intentando buscar puentes entre aquella y este. Se trataría de que la enseñanza en español (L2) no impidiera el bilingüismo aditivo, permitiendo el desarrollo de la L1 y en un futuro, o en consonancia, después de que la lectoescritura en la L1 tenga una buena base, se pueda acceder a otra L2, el árabe literal.

Si nos centramos en el árabe marroquí o el amazige como L1, diremos, como de cualquier lengua, que posee un nivel de "dominio comunicacional" general, basado en la interrelación cotidiana, y otro particular cuyo nivel es de "dominio académico" ${ }^{2}$, que la escuela debe contribuir a desarrollar. En este sentido, el autor antes citado pone de manifiesto cómo los niños inmigrantes adquieren el "dominio comunicacional" de forma fluida, pero dice hacen falta al menos cinco años o más para conseguir "el dominio académico" en la L2 ${ }^{63}$. Esta situación puede ser trasladada a los niños ceutíes españoles que empiezan a adquirir el español a la edad de tres años cuando llegan a la etapa infantil del sistema educativo ${ }^{64}$. Y así, el acceso al "dominio académico" de un niño ceutí bilingüe puede ser más lento que el de un monolingüe, y aunque su "dominio conversacional" se encuentre al mismo nivel, si, como hemos advertido previamente, la enseñanza no se ha producido a través de un bilingüismo aditivo, el "dominio académico" en español del bilingüe se verá seriamente resentido, siendo esta una causa importante del fracaso escolar ceutí. En otras palabras, el niño podrá pasar por un hablante en español como si fuera su lengua nativa, pero le será muy difícil comprender, conforme pasan los años en la escuela, el registro de español en el que el profesor enseña los contenidos académicos. Para Cummins, podremos reconocer un adecuado progreso en el "dominio académico" si "los alumnos están generando nuevos conocimientos, creando literatura y arte y actuando sobre las realidades sociales que afectan a sus vidas" ${ }^{\circ 5}$. La situación es muy preocupante, ya que si la escuela no contribuye a una educación bilingüe aditiva, el "dominio académico" en L1 será nulo y el de la L2 se verá resentido considerablemente. Y si además, el programa de LACM enseña el árabe literal, que consideramos una L2, el resultado puede ser el de un niño que fracasa en la escuela o que consigue superar la etapa educativa habiendo adquirido un "dominio académico" en español considerable, pero que ha perdido esta competencia en su L1 y que además no ha podido alcanzar ni un "dominio conversacional" ni un "dominio académico" aceptable en árabe literal.

No se trata en lo que vamos a exponer a continuación de colocar en un pódium inferior al lenguaje comunicativo y en uno superior al lenguaje académico, los dos

\footnotetext{
${ }^{62}$ Cf. CUMMINS, Lenguaje, 93.

${ }^{63}$ Cf. CUMMINS, Lenguaje, 94.

${ }^{64}$ Cf. RIVERA REYES, «Características del bilingüismo... », pág. 228.

${ }^{65} \mathrm{Cf}$. CUMMINS, Lenguaje, 119.
} 
son importantes en el desarrollo de la L1, pero nos detendremos en el segundo de ellos. Debemos de contar con material escrito en árabe marroquí y este cada vez existe en mayor cantidad, aunque todavía no hay una política que permita la normalización de un código de escritura concreto, ni en Marruecos ni en España. Marruecos no reconoce ni siquiera como lengua nacional al árabe marroquí. Tan solo, en la reforma de la Constitución que hubo en 2011 se añadió una segunda lengua cooficial, el amazige, a la única existente hasta el momento, el árabe, entendiéndose por este el literal o clásico. Por otro lado, cuando se habla de amazige no se hace referencia a las tres grandes variantes de este, que son auténticas lenguas, el tarifit, el tamazight y el tachelhit. En otros artículos hemos abordado esta cuestión y ofrecido ejemplos de textos y la codificación que nos parece más acertada para el árabe marroquí, es decir la propuesta por el profesor Abderrahim Youssi en las traducciones de obras literarias europeas al árabe marroquí y en la preparación de una gramática de esta lengua que pronto publicará ${ }^{66}$. Todo este material, además de la tradición oral que ya ha sido recogida por escrito y otras producciones, tendrían que emplearse para el desarrollo de la lectoescritura del niño y para seguir escribiendo en árabe marroquí, nutriéndolo de nuevos términos y expresiones, procedentes fundamentalmente del árabe literal, que ayuden a expresar en esta lengua conceptos e ideas de todas las disciplinas. Podremos ir midiendo el lenguaje académico del alumno, y su evolución hacia estadios más avanzados, a través del léxico y su carga conceptual que deben de ir en constante aumento gracias a la lectoescritura, permitiendo el desarrollo cognitivo del discente ${ }^{67}$.

El "dominio académico" adquirido en la L1 se transfiere a la L2, es decir, la adecuada adquisición de la lectoescritura en la L1 ayudará al aprendizaje de esta en la L $2^{68}$. Partiendo de este supuesto, proponemos que el árabe marroquí o el amazige sean enseñados como L1 en el programa de LACM, de tal forma que, más adelante, la L2, ya sea el español o el árabe literal, tenga un mejor progreso en el aprendizaje de su lectoescritura. En el caso del español, al ser una lengua con raíces diferentes de la árabe, la transferencia se llevará a cabo sobre todo en el terreno cognitivo y de personalidad, mientras que en el caso del árabe literal, la transferencia se apoyará además en las afinidades lingüísticas ${ }^{69}$. Lo que está claro es que someter al alumno solo al estudio académico en una L2, marginando su L1, conlleva, en muchos casos, un fracaso. Al contrario, el desarrollo de ambas lenguas desembocará en unos resultados cognitivos, académicos y metalingüísticos aceptables tanto en una como en otra. Una cuestión que habría que plantearse, apoyándose en ensayos y estudios hechos en otras partes del mundo, es cómo enseñar la lectoescritura en L1 para

\footnotetext{
${ }^{66} \mathrm{Cf}$. MOSCOSO, «De Ibn Jaldún al reconocimiento del árabe marroquí...», 147.

${ }^{67} \mathrm{Cf}$. CUMMINS, Lenguaje, 84.

${ }^{68} \mathrm{Cf}$. CUMMINS, Lenguaje, 199.

${ }^{69} \mathrm{Cf}$. CUMMINS, Lenguaje, 211.
} 
nuestros alumnos de origen marroquí o nacionales cuya lengua nativa es el árabe marroquí o el amazige. ¿Se enseñarían las lectoescrituras de L1 y L2 al mismo tiempo o se dedicaría primero un período de tiempo a la adquisición de la L1? Nuestro parecer es el de empezar al mismo tiempo, estableciendo puentes tanto a nivel conceptual como lingüístico entre la L1 y L2, promoviendo así una actitud positiva hacia la lengua nativa y otras lenguas, tanto en alumnos como en profesores. Que la educación bilingüe funciona es un hecho que se ha verificado en muchas partes del mundo, mostrando resultados mejores que los programas monolingües ${ }^{70}$.

¿Por qué entonces el gobierno español no fomenta la lengua nativa de los inmigrantes o de los españoles bilingües de Ceuta? La respuesta más plausible a esta pregunta es que los que dominan el establishment no desean que las minorías accedan con pleno derecho, es decir, con su lengua nativa en un desarrollo de "dominio académico", a las esferas de poder público. Y esto, por miedo a la igualdad de oportunidades y al cambio que ello generaría en nuestra sociedad. Perdemos bastante, desde democracia a desarrollo humano y económico, con todo lo que ello podría traer consigo de riqueza lingüística, humana y progreso. Lo contrario, lo que puede producirse, será empobrecimiento y situaciones de intolerancia que desembocarán inevitablemente en conductas racistas y xenófobas. Por consiguiente, "[...] debemos construir una pedagogía que inicie y mantenga un diálogo vivo entre oprimidos y opresores, en el que ambos grupos puedan entender las constricciones sociales que inhiben el progreso hacia una democracia emancipadora y se conciencien más de las diferentes formas de opresión que experimenta cada grupo"’1. Así pues, proponemos a las autoridades españoles que se conciencien de la importancia que conlleva la enseñanza de la lengua nativa a todos los niveles y que reconozcan el derecho constitucional de las minorías nacionales y de los grupos de ciudadanos originarios de Marruecos. Igualmente, sería necesario que este último país tomara en consideración la enseñanza de la lengua nativa en la escuela para que la adquisición de la L2 (árabe literal) sea más efectiva. Solo así podremos ir creciendo en sociedad, dejando a un lado la relación coercitiva del sistema monolingüe y abriendo nuevas puertas al diálogo entre los organismos educativos, docentes, discentes y padres, que permitan el enriquecimiento cultural y lingüístico en nuestras escuelas.

\section{CONCLUSIONES}

El Programa de Lengua Árabe y Cultura Marroquí (LACM) no contempla la enseñanza de la L1 (árabe marroquí o amazige) en sus objetivos, sencillamente porque el sistema educativo marroquí no lo hace. La LOGSE en España ofrece la

\footnotetext{
${ }^{70} \mathrm{Cf}$. CUMMINS, Lenguaje, 243.

${ }^{71}$ Cf. CUMMINS, Lenguaje, 268.
} 
posibilidad para la "educación en la diversidad". Debemos de aprovechar esta coyuntura para proponer que la lengua nativa de los ciudadanos de origen marroquí en general, y en particular la población bilingüe de Ceuta, sea tenida en cuenta en la escuela en un contexto de bilingüismo aditivo. Solo así, el niño podrá alcanzar un desarrollo cognitivo óptimo en su L1, que le ayudará a la hora de adquirir la L2, el español o el árabe literal. Valorar la lengua nativa significa terminar con una situación de opresión que el poder educativo monolingüe mantiene como garante de sus intereses frente a los grupos más desprotegidos. Esta situación también es una llamada de atención a nuestros planes de estudios de árabe universitarios para que desarrollen aún más en sus currículos el estudio de la lengua nativa de la población de origen árabe más importante de nuestro país, a saber, el árabe marroquí, pero también la lengua amazige, tan importante en número de hablantes en Marruecos. 